\title{
Relationship between falls, knee osteoarthritis, and health-related quality of life: data from the Osteoarthritis Initiative study
}

This article was published in the following Dove Press journal:

Clinical Interventions in Aging

8 May 2014

Number of times this article has been viewed

\section{Vishal Vennu \\ Saad M Bindawas \\ Department of Rehabilitation Science, College of Applied Medical Sciences, King Saud University, Riyadh, Saudi Arabia}

Background: The purpose of this study was to examine the relationship between self-reported falls, doctor-diagnosed knee osteoarthritis (OA), and health-related quality of life (HRQoL). We hypothesized that falls and knee OA would be associated with poor HRQoL on both disease-specific and generic measures.

Methods: This cross-sectional study used data from the publicly available Osteoarthritis Initiative data sets. A total of 4,484 subjects aged 45-79 years at baseline were divided into three subpopulations: those who had neither a history of falling nor doctor-diagnosed knee OA; those who had either a self-reported history of falling or doctor-diagnosed knee OA; and those who had both a self-reported history of falling and doctor-diagnosed knee OA. HRQoL was assessed using both disease-specific and generic measures. Multiple regression analyses were used to examine the relationship between self-reported falls, doctor-diagnosed knee OA, and HRQoL assessed using the Knee Injury and Osteoarthritis Outcome Score-Quality of Life (KOOS-QoL) subscale and two Short Form-12 (SF-12) summary scales. The models were adjusted for participant sociodemographic, lifestyle, and clinical characteristics.

Results: Falls and knee OA were significantly associated with lower scores on the KOOS-QoL $(\beta=-34.4$, standard error $2.27, P \leq 0.0001)$ and on the physical component scale of the SF-12 ( $\beta=-9.44$, standard error $0.90, P<0.0001)$. No significant relationship was found with the mental component scale score when adjusted for sociodemographic, lifestyle, and clinical characteristics.

Conclusion: When compared with those having neither a self-reported history of falling nor doctor-diagnosed knee OA and those with a self-reported history of falling or doctor-diagnosed knee OA, persons with both conditions (falls and knee OA) had significantly lower KOOS-QoL and physical component scale scores after adjusting for sociodemographic, lifestyle, and clinical characteristics. Future research should assess potential mediating factors in an effort to improve HRQoL in persons with knee OA who are at high risk of falling.

Keywords: osteoarthritis, quality of life, falls

\section{Introduction}

Falls in adults pose a major health concern, are a well-known public health problem, ${ }^{1}$ and are the main cause of injury, hospitalization, disability, poor quality of life, depression, and mortality in older adults. ${ }^{2,3}$ About $30 \%-40 \%$ of adults in the USA report falling at least once per year, ${ }^{4}$ but less than half discuss their falls with their health care provider. ${ }^{5}$ One of the most common biological risk factors for falls is sarcopenia, which is observed in knee osteoarthritis (OA). ${ }^{6}$

Knee OA is an important risk factor for falls, particularly in women. ${ }^{7}$ In the USA, about $40 \%$ of adults with knee OA reported their health as "poor" or "fair", and
Correspondence:Vishal Vennu

Department of Rehabilitation Science,

College of Applied Medical Sciences, King

Saud University, PO Box 10219, Riyadh

I I 433, Saudi Arabia

Tel +966I I4693550

Email vvennu@ksu.edu.sa 
more than $50 \%$ of those with knee OA reported falling in the previous year. ${ }^{8}$ As the number of older adults increases, it is expected that the prevalence of falls and knee OA will increase. ${ }^{8,9}$ In 2010, the overall rate of falls and fall-related injury was 43 per 1,000 population. ${ }^{9}$ An estimated 42.7 million Americans (15\% of the population) had knee OA in 1995 , and, because of the increasing average age of the population, this figure is projected to rise to 59.4 million (18.2\%) by $2020 .{ }^{10}$ Because of this growing epidemic, it is important to understand and monitor the impact of falls and knee OA on physical and mental health.

One health outcome of particular interest in patients with falls and knee OA is health-related quality of life (HRQoL). ${ }^{11}$ Assessment of HRQoL has received considerable attention in recent decades. ${ }^{12}$ A key reason for serial measurement of HRQoL is to reflect the changes that occur in an individual's health state in response to disease progression, various therapies, and recovery. ${ }^{12}$ There are a variety of generic and knee-specific instruments available to assess HRQoL in people with OA. ${ }^{13}$ The Knee Injury and Osteoarthritis Outcome Score (KOOS) is a knee-specific instrument, while the Short Form-12 (SF-12) is a generic measure developed to assess HRQoL in persons who have had falls during the previous 12 months.

The objective of this study was to examine the relationship between self-reported falls, doctor-diagnosed knee OA, and HRQoL using both disease-specific and generic measures. We selected the KOOS-QoL subscale as a disease-specific measure and the SF-12 as a generic measure because they are widely used to assess HRQoL and have been validated for the subpopulation of patients with self-reported falls and doctor-diagnosed knee OA.

\section{Materials and methods}

The Osteoarthritis Initiative is a publicly and privately funded, ongoing, longitudinal multicenter study of the onset and progression of knee OA. ${ }^{14}$ Adults aged 45-79 years at enrollment who had or were at high risk of knee OA were recruited between February 2004 and May 2006 from four clinical sites in the USA, ie, Baltimore, MD; Pittsburgh, PA; Pawtucket, RI; and Columbus, $\mathrm{OH}$.

Details regarding the Osteoarthritis Initiative, including study overview, objectives, collaboration worldwide, funding, resources, visit schedule, and assessments are described elsewhere. ${ }^{15}$ The study protocol was approved by the institutional review board at the center coordinating the Osteoarthritis Initiative at the University of California, San Francisco, CA, USA. ${ }^{14}$

\section{Study sample}

The data used for the present study were obtained from the study documentation and data publically available in the online Osteoarthritis Initiative database. ${ }^{14}$ The specific dataset used was version 0.2.2 ( $\mathrm{n}=4,796$, November 2008). We considered three subpopulations according to selfreported history of falling and doctor-diagnosed knee OA status as follows: those had neither a self-reported history of falling nor doctor-diagnosed knee OA; those who had either a self-reported history of falling or doctor-diagnosed knee OA; and those who had both a selfreported history of falling and doctor-diagnosed knee OA. Subjects were included if they were aged 45-79 years, regardless of sex or ethnicity (Figure 1). We excluded individuals who did not know, were not sure, or refused to answer ( $<6.5 \%$ of the 4,312 respondents $)^{14}$ from the analysis (Figure 1).

\section{Measurements}

History of self-reported falling and doctor-diagnosed knee OA had been assessed using the following questions: "Have you fallen and landed on the floor or ground in the past 12 months?"16 and "Has the doctor said you have osteoarthritis/degenerative arthritis of the knee?"17 Respondents were defined as having neither a self-reported history of falling nor knee OA if they had answered "no" to both the above questions, and to have either a self-reported history

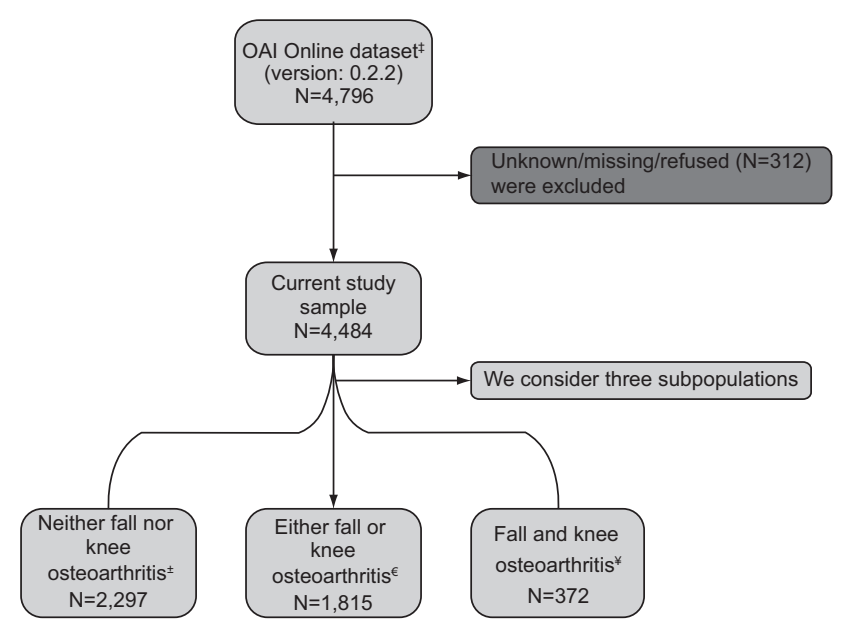

Figure I Flow diagram of selection and classification of subjects enrolled in the Osteoarthritis Initiative study that was included in the present study.

Notes: $¥$ OAl (Osteoarthritis Initiative) Online database provided by coordinating center, University of California, San Francisco (http://oai.epi-ucsf.org/datarelease/); ${ }^{ \pm}$neither fall nor knee osteoarthritis defined as persons with neither a self-reported history of falls nor doctor-diagnosed knee osteoarthritis; $\epsilon$ either fall or knee osteoarthritis defined as persons with a self-reported history of falls or doctordiagnosed knee osteoarthritis; ${ }^{*}$ fall and knee osteoarthritis defined as persons with a self-reported history of falls and doctor-diagnosed knee osteoarthritis. 
of falling or knee OA if they answered "no" to only one of the above questions.

HRQoL was assessed using both disease-specific and generic measures. ${ }^{18}$ The KOOS-QoL ${ }^{18}$ was used as the kneespecific measure and the SF- $12^{19}$ as the generic measure.

The KOOS was developed to assess patients' opinions regarding their knees and associated problems. The KOOS consists of five subscales, ie, pain, other symptoms, ability to perform activities of daily living, function in sports and recreation. The KOOS-QoL subscale was used in this study and consists of four items, ie, knee problems, knee activity, knee troubles, and knee difficulty. Each subscale score ranges from 0 (no problems) to 4 (extreme problems), and was calculated as the sum of the above four items. The scores are transformed using a 0-100 scale, with zero representing extreme problems and 100 representing no problems. ${ }^{20}$ Responses of "don't know" and "refused" were treated as missing data.

The SF-12 scale, a shorter version of the SF-36 scale, uses 12 questions to measure the following eight dimensions of health: physical function, role limitations related to physical problems, pain, general health perception, vitality, social functioning, role limitations due to emotional problems, and mental health. These dimensions can be categorized into a physical component scale (PCS) and a mental component scale (MCS). These health concepts are described by normbased scores, with a mean of 50 in the general population and higher scores indicating better heath. ${ }^{21}$

The demographic and socioeconomic variables included were age (years), race (White versus non-White), sex (female versus male), education (high school/less versus some college/graduation), marital status (married versus unmarried), employment (employed versus unemployed), annual income (<US\$50,000 versus $\geq$ US\$50,000), household composition (single versus living with others), smoking status (never versus current), and weekly alcoholic consumption (never versus current). Validated general health measures of comorbidity and depression (high versus low) were used. The Carlson Cormorbidity Index was used to measure comorbidity. ${ }^{19}$ A score $\geq 16$ on the Center for Epidemiological Studies Depression scale was taken to indicate severe depressive symptoms. ${ }^{22}$

\section{Statistical analysis}

The sample characteristics were described using the mean and standard deviation for continuous variables and the frequency (number and percentage) for categoric variables. We used analysis of variance for continuous covariates and the chi-square test for categoric covariates to examine differences in sample characteristics and covariates according to self-reported history of falling and doctordiagnosed knee OA status.

Multiple regression analyses were used to examine the relationship between falls and knee OA status on the KOOS-QoL and SF-12 (PCS and MCS). Two models were used to test these associations. Model 1 examined the unadjusted relationship between falls and knee OA status on the KOOS-QoL and SF-12 (PCS and MCS). Model 2 investigated whether the relationship between falls and knee OA status on the KOOS-QoL and SF-12 (PCS and MCS) was affected by sociodemographic, lifestyle, and clinical characteristics (ie, sex, race, education, marital status, employment, household composition, annual income, health care coverage, smoking status, alcohol consumption, comorbidity, and depressive symptoms).

\section{Results}

Of the 4,484 participants, 2,297 (51.23\%) had neither a self-reported history of falling nor doctor-diagnosed knee OA, 1,815 (40.48\%) had either a history of falling or knee OA, and $372(8.30 \%)$ had both a history of falling and knee OA (Table 1). Those who had both a history of falling and knee OA were significantly more likely to be women, have a lower income, report more depressive symptoms, partake in less physical activity, and have a lower HRQoL score than the other two groups.

Table 2 shows the regression analysis for self-reported history of falling and doctor-diagnosed knee OA status according to the KOOS-QoL. In model 1 (unadjusted), either a history of falling or knee OA was significantly associated with KOOS-QoL score $(\beta=-19.7$, standard error $1.35, P<0.0001)$ compared with no history of falling or knee OA. Having both a history of falling and knee OA was more strongly associated with KOOS-QoL score $(\beta=-39.5$, standard error 2.38, $P<0.0001)$ compared with neither a history of falling or knee OA and either a history of falling or knee OA (Table 2). In model 2, when sociodemographic, lifestyle, and clinical characteristics (sex, race, education, marital status, employment, household composition, annual income, health care coverage, smoking status, alcohol consumption, comorbidity, and depressive symptoms) were added, the negative association with KOOS-QoL score was statistically significant ( $\beta=-18.5$, standard error $1.29, P<0.0001$ ) in persons with either a history of falling or knee OA compared with persons who had no history of falling or knee OA. Having both a history of falling and knee OA was more strongly associated with KOOS-QoL score $(\beta=-34.4$, standard error $2.27, P<0.0001)$ 
Table I Descriptive characteristics of participants stratified by falls and knee OA status

\begin{tabular}{|c|c|c|c|c|c|}
\hline Characteristics & All $n=4,484$ & $\begin{array}{l}\text { Neither fall nor } \\
\text { knee OA } n=2,297\end{array}$ & $\begin{array}{l}\text { Either fall or } \\
\text { knee OA } n=I, 8 \text { I } 5\end{array}$ & $\begin{array}{l}\text { Fall and } \\
\text { knee OA } n=372\end{array}$ & $P$-value \\
\hline \multicolumn{6}{|l|}{ Demographic } \\
\hline Age, years & $61.0 \pm 9.1$ & $61.0 \pm 9.3$ & $61.2 \pm 9.0$ & $61.4 \pm 9.1$ & 0.48 \\
\hline Sex & & & & & 0.0002 \\
\hline Male & $\mathrm{I}, 848(4 \mathrm{I} .2 \mathrm{I})$ & $\mathrm{I}, 004(54.33)$ & 719 (38.91) & $125(6.76)$ & \\
\hline Female & $2,636(58.79)$ & I,293 (49.05) & $\mathrm{I}, 096(4 \mathrm{I} .58)$ & $247(9.37)$ & \\
\hline Ethnicity & & & & & 0.81 \\
\hline White or Caucasian & $3,542(78.99)$ & I,8I7 (5I.30) & $\mathrm{I}, 436(40.54)$ & $289(8.16)$ & \\
\hline Non-White & $942(21.01)$ & $480(50.96)$ & $379(40.23)$ & $83(8.8 \mathrm{I})$ & \\
\hline Education & & & & & 0.34 \\
\hline High school or less & $729(16.26)$ & $356(48.83)$ & $307(42.11)$ & $66(9.05)$ & \\
\hline Some college/graduation & $3,755(83.74)$ & I,94I (5I.69) & I,508 (40.16) & $306(8.15)$ & \\
\hline Divorced/separated & $\mathrm{I}, 090(24.3 \mathrm{I})$ & $525(48.17)$ & $465(42.66)$ & $100(9.17)$ & 0.06 \\
\hline Employed & $2,799(62.42)$ & I,463 (52.27) & I,I $24(40.16)$ & $212(7.57)$ & 0.040 \\
\hline Annual income $<$ US $\$ 50,000$ & I,677 (37.40) & $829(49.43)$ & $677(40.37)$ & $|7|(\mid 0.20)$ & 0.0013 \\
\hline Household composition & & & & & 0.18 \\
\hline Living alone & $1,002(22.35)$ & $489(48.80)$ & 421 (42.02) & $92(9.18)$ & \\
\hline Living with others & $3,482(77.65)$ & I,808 (5।.92) & I,394 (40.03) & $280(8.04)$ & \\
\hline \multicolumn{6}{|l|}{ Lifestyle } \\
\hline Smoking & & & & & 0.56 \\
\hline Never & $302(6.74)$ & $152(50.33)$ & $120(39.74)$ & $30(9.93)$ & \\
\hline Current & $4,182(93.26)$ & $2,145(51.29)$ & $\mathrm{I}, 695(40.53)$ & $342(8.18)$ & \\
\hline Alcohol consumption & & & & & 0.56 \\
\hline Never & $881(19.65)$ & $457(51.87)$ & $345(39.16)$ & 79 (8.97) & \\
\hline Yes & $3,603(80.35)$ & $\mathrm{I}, 840(5 \mathrm{I} .07)$ & $\mathrm{I}, 470(40.80)$ & $293(8.13)$ & \\
\hline \multicolumn{6}{|l|}{ Clinical } \\
\hline Comorbidity score & & & & & $<0.000$ I \\
\hline 0 & $3,353(74.78)$ & I,794 (53.50) & I,3II (39.10) & $248(7.40)$ & \\
\hline$\geq 1$ & $\mathrm{I}, \mathrm{I} 3 \mathrm{I}(25.22)$ & $503(44.47)$ & $504(44.56)$ & $124(10.96)$ & \\
\hline Depression scale (CESD) & & & & & $<0.0001$ \\
\hline No symptoms & $4,026(89.79)$ & $2,111(52.43)$ & $1,616(40.14)$ & $299(7.43)$ & \\
\hline Depressive symptoms & $458(10.21)$ & $186(40.16)$ & $199(43.45)$ & $73(15.94)$ & \\
\hline \multicolumn{6}{|l|}{ Self-reported quality of life } \\
\hline PASE score & $\mid 57.7 \pm 83.1$ & $163.0 \pm 80.7$ & $160.7 \pm 83.8$ & $149.6 \pm 85.0$ & 0.015 \\
\hline KOOS-QoL score & $61.8 \pm 21.2$ & $73.1 \pm 20.6$ & $63.3 \pm 22.8$ & $49.0 \pm 20.3$ & $<0.0001$ \\
\hline SF-12 PCS score & $47.3 \pm 9.3$ & $50.7 \pm 8.0$ & $47.6 \pm 9.5$ & $43.6 \pm 10.4$ & $<0.0001$ \\
\hline SF-12 MCS score & $53.0 \pm 8.6$ & $54.0 \pm 7.5$ & $53.4 \pm 8.4$ & $51.6 \pm 10.0$ & $<0.000$ I \\
\hline
\end{tabular}

Note: Data are shown as the mean \pm standard deviation or $\mathrm{N}(\%)$.

Abbreviations: KOOS-QoL, Knee Injury and Osteoarthritis Outcome Score-Quality of Life subscale; PCS, physical component scale; OA, osteoarthritis; MCS, mental component scale; PASE, Physical Activity Scale for Elderly; SF-12, Short Form-I2; CESD, Center for Epidemiologic Studies Depression Scale.

compared with no history of falling or knee OA and compared with either a history of falling or knee OA. Other variables significantly associated with KOOS-QoL scores in model 2 were age, sex, race, education, employment, income, smoking, depression, and comorbidity (see Table 2).

The regression analysis of history of falling and doctor-diagnosed knee OA status on the PCS and MCS of the SF-12 is shown in Tables 3 and 4, respectively. In model 1 (unadjusted), either a history of falling or knee OA were significantly associated with PCS and MCS scores $(\beta=-6.1$, standard error $0.55, P<0.0001$, and $\beta=-1.1$, standard error $0.50, P=0.030$, respectively) than neither a history of falling nor knee OA. Having both a history of falling and knee OA was more strongly associated with PCS and MCS scores $(\beta=-11.4$, standard error $0.98, P<0.0001$, and $\beta=-4.20$, standard error $0.88, P<0.0001$, respectively) than neither a history of falling nor knee OA or either a history of falling or knee OA (see Tables 3 and 4). In model 2, when sociodemographic, lifestyle, and clinical characteristics (sex, race, education, marital status, employment, household 
Table 2 Regression analysis for the KOOS-QoL subscale stratified by falls and knee OA status

\begin{tabular}{|c|c|c|c|c|c|c|}
\hline \multirow[t]{2}{*}{ Variables } & \multicolumn{3}{|c|}{ Model I } & \multicolumn{3}{|c|}{ Model 2} \\
\hline & $\beta$ & SE & $P$-value & $\beta$ & SE & P-value \\
\hline Intercept & 56.2 & 0.93 & $<0.0001$ & 53.2 & 3.79 & $<0.0001$ \\
\hline Neither fall nor knee OA & \multicolumn{3}{|c|}{ Reference } & \multicolumn{3}{|c|}{ Reference } \\
\hline Either fall or knee OA & -19.7 & 1.35 & $<0.0001$ & -18.5 & 1.29 & $<0.0001$ \\
\hline Neither fall nor knee OA and either fall or knee OA & \multicolumn{3}{|c|}{ Reference } & \multicolumn{3}{|c|}{ Reference } \\
\hline Fall and knee OA & -39.5 & 2.38 & $<0.0001$ & -34.4 & 2.27 & $<0.0001$ \\
\hline Age & & & & 0.29 & 0.040 & $<0.0001$ \\
\hline Sex (females versus males) & & & & -0.16 & 0.073 & 0.026 \\
\hline Race (Whites versus non-Whites) & & & & -0.78 & 0.092 & $<0.0001$ \\
\hline Education (high school/less versus some college/graduation) & & & & -0.23 & 0.10 & 0.021 \\
\hline Marital status (divorced/separated versus married) & & & & 0.10 & 0.10 & 0.29 \\
\hline Employment status (employed versus unemployed) & & & & -0.31 & 0.08 & 0.0002 \\
\hline Annual income $(<$ US $\$ 50,000$ versus $>$ US $\$ 50,000)$ & & & & 0.18 & 0.08 & 0.024 \\
\hline Household composition (living single versus living with others) & & & & -0.03 & 0.10 & 0.76 \\
\hline Smoking status (current versus never) & & & & -0.37 & 0.14 & 0.009 \\
\hline Alcohol consumption (yes versus no) & & & & -0.06 & 0.09 & 0.55 \\
\hline Comorbidity (yes versus no) & & & & 0.34 & 0.08 & $<0.0001$ \\
\hline Depressive symptoms (yes versus no) & & & & 0.89 & 0.11 & $<0.0001$ \\
\hline
\end{tabular}

Abbreviations: OA, osteoarthritis; KOOS-QoL, Knee Injury and Osteoarthritis Outcome Score-Quality of Life; SE, standard error.

composition, annual income, health care coverage, smoking status, alcohol consumption, comorbidity, and depressive symptoms) were added, there was a statistically significant negative relationship with PCS score $(\beta=-5.56$, standard error $0.50, P<0.0001)$ in persons with either a history of falling or knee OA compared with persons who had no history of falling or knee OA. Having both a history of falling and knee OA was more strongly associated with PCS score $(\beta=-9.44$, standard error $0.90, P<0.0001)$ compared with no history of falling or knee OA and compared with either a history of falling or knee OA (see Table 3). However, no statistically significant relationship was found with MCS score (see Table 4). Other variables that were significantly associated with PCS scores in model 2 were race, education, employment, income, smoking status, alcohol consumption, depression, and comorbidity (see Table 3 ). Variables significantly associated with MCS scores in model 2 were age, race, marital status, income, smoking, and depression (see Table 4).

Table 3 Regression analysis on the physical component scale of the Short Form- 12 stratified by OA status

\begin{tabular}{|c|c|c|c|c|c|c|}
\hline \multirow[t]{2}{*}{ Variables } & \multicolumn{3}{|c|}{ Model I } & \multicolumn{3}{|c|}{ Model 2} \\
\hline & $\beta$ & SE & $P$-value & $\beta$ & SE & P-value \\
\hline Intercept & 46.2 & 0.69 & $<0.0001$ & 42.8 & 1.20 & $<0.0001$ \\
\hline Neither fall nor knee OA & \multicolumn{3}{|c|}{ Reference } & \multicolumn{3}{|c|}{ Reference } \\
\hline Either fall or knee OA & -6.1 & 0.55 & $<0.0001$ & -5.56 & 0.50 & $<0.0001$ \\
\hline Neither fall nor knee OA and either fall or knee OA & \multicolumn{3}{|c|}{ Reference } & \multicolumn{3}{|c|}{ Reference } \\
\hline Fall and knee OA & -11.4 & 0.98 & $<0.0001$ & -9.44 & 0.90 & $<0.0001$ \\
\hline Age & & & & 0.006 & 0.016 & 0.68 \\
\hline Sex (females versus males) & & & & 0.021 & 0.029 & 0.46 \\
\hline Race (Whites versus non-Whites) & & & & -0.37 & 0.036 & $<0.0001$ \\
\hline Education (high school/less versus some college/graduation) & & & & -0.16 & 0.04 & $<0.0001$ \\
\hline Marital status (divorced/separated versus married) & & & & 0.013 & 0.041 & 0.74 \\
\hline Employment status (employed versus unemployed) & & & & -0.25 & 0.03 & $<0.0001$ \\
\hline Annual income $(<$ US $\$ 50,000$ versus $>$ US $\$ 50,000)$ & & & & 0.23 & 0.032 & $<0.0001$ \\
\hline Household composition (living alone versus living with others) & & & & -0.02 & 0.04 & 0.55 \\
\hline Smoking status (current versus never) & & & & -0.21 & 0.057 & 0.0002 \\
\hline Alcohol consumption (yes versus no) & & & & -0.13 & 0.036 & 0.0002 \\
\hline Comorbidity (yes versus no) & & & & 0.36 & 0.032 & $<0.0001$ \\
\hline Depressive symptoms (yes versus no) & & & & 0.23 & 0.04 & $<0.0001$ \\
\hline
\end{tabular}

Abbreviations: OA, osteoarthritis; SE, standard error. 
Table 4 Regression analysis on the mental component scale of the Short Form- 12 stratified by fall and knee OA status

\begin{tabular}{|c|c|c|c|c|c|c|}
\hline \multirow[t]{2}{*}{ Variables } & \multicolumn{3}{|c|}{ Model I } & \multicolumn{3}{|c|}{ Model 2} \\
\hline & $\beta$ & SE & $P$-value & $\beta$ & SE & $P$-value \\
\hline Intercept & 52.5 & 0.30 & $<0.0001$ & 28.6 & 0.95 & $<0.0001$ \\
\hline Neither fall nor knee OA & \multicolumn{3}{|c|}{ Reference } & \multicolumn{3}{|c|}{ Reference } \\
\hline Either fall or knee OA & -1.1 & 0.50 & 0.030 & -0.24 & 0.40 & 0.56 \\
\hline Neither fall nor knee OA and either fall or knee OA & \multicolumn{3}{|c|}{ Reference } & \multicolumn{3}{|c|}{ Reference } \\
\hline Fall and knee $O A$ & -4.20 & 0.88 & $<0.0001$ & -0.79 & 0.71 & 0.26 \\
\hline Age & & & & 0.13 & 0.013 & $<0.0001$ \\
\hline Sex (females versus males) & & & & 0.034 & 0.022 & 0.14 \\
\hline Race (Whites versus non-Whites) & & & & 0.084 & 0.028 & 0.0033 \\
\hline Education (high school/less versus some college/graduation) & & & & -0.03 & 0.03 & 0.23 \\
\hline Marital status (divorced/separated versus married) & & & & 0.09 & 0.032 & 0.0034 \\
\hline Employment status (employed versus unemployed) & & & & -0.02 & 0.026 & 0.36 \\
\hline Annual income $(<\cup S \$ 50,000$ versus $>$ US $\$ 50,000)$ & & & & 0.086 & 0.025 & 0.0008 \\
\hline Household composition (living alone versus living with others) & & & & 0.005 & 0.032 & 0.86 \\
\hline Smoking status (current versus never) & & & & -0.17 & 0.045 & $<0.0001$ \\
\hline Alcohol consumption (yes versus no) & & & & -0.02 & 0.028 & 0.33 \\
\hline Comorbidity (yes versus no) & & & & 0.04 & 0.025 & 0.14 \\
\hline Depressive symptoms (yes versus no) & & & & 1.65 & 0.037 & $<0.0001$ \\
\hline
\end{tabular}

Abbreviations: OA, osteoarthritis; SE, standard error.

\section{Discussion}

The aim of the current study was to examine the relationship between self-reported history of falling, doctor-diagnosed knee OA, and HRQoL. We found that self-reported history of falling and doctor-diagnosed knee OA were significantly associated with poorer quality of life according to the KOOS-QoL subscale and the PCS of the SF-12, after controlling for all covariates.

We used both disease-specific (KOOS-QoL subscale) and generic (SF-12) HRQoL measures to capture different aspects of the health status of the study population. ${ }^{23}$ Although a history of falling and knee OA were associated with poorer HRQoL, the PCS domain of the SF-12 and the QoL domain of the KOOS-QoL subscale showed significantly lower score in persons with both conditions (fall and knee OA) compared with persons who had no history of falling or knee OA and persons with either a history of falling or knee OA. The lower scores on the PCS and HRQoL domains indicate a significant determinant worthy of further evaluation over a longer follow-up duration. We had expected to find low PSC scores on the SF-12 and on the KOOS-QoL subscale when investigating how a history of falling and having knee OA affects these constructs at baseline.

According to our data, individuals who had experienced falls and had knee OA showed lower MCS scores even after adjustment for sociodemographic, lifestyle, and clinical characteristics, compared to persons who had no history of falling or knee OA and persons with either a history of falling or knee OA. This difference in MCS scores suggests that depressive symptoms impact areas beyond physical function. Previous research has identified adverse effects of falling and knee OA across different dimensions of HRQoL, including mental health. ${ }^{24}$ For example, Chen et $\mathrm{al}^{25}$ found that persons with a history of falling and knee OA had more comorbid mental health conditions and were at greater risk of anxiety and depression than those with neither a history of falling nor knee OA.

Our findings support the call for continued research on interventions that address self-reported fall and doctor diagnosed knee OA to improve HRQoL. ${ }^{26}$ We can reduce falls by providing effective falls prevention programs for adults in our communities. Such measures can help the elderly to enjoy better and longer lives. The Centers for Disease Control and Prevention has reviewed and identified community-based fall prevention interventions with strong scientific evidence of effectiveness. ${ }^{27}$

Research has shown that arthritis conditions, including knee OA, have vast impact on quality of life. ${ }^{28}$ Our study also confirms that having both conditions (fall and knee OA) are significantly associated with poorer HRQoL compared with persons who had no history of falling or knee OA and persons with either a history of falling or knee OA.

The presence of knee OA has been shown to be a risk factor for falls. ${ }^{29}$ It makes sense that the presence of knee OA has the greatest impact on fall risk, and functional ability (eg, gait, ability to rise from a chair) shows direct associations with fall frequency. ${ }^{30}$ Consistent with our findings, Sturnieks et al found an increased risk of falls in adults with knee OA relative to a sample of healthy adults. ${ }^{31}$ 
Our study has several strengths. To our knowledge, it is the first to examine HRQoL in relation to self-reported falls and doctor-diagnosed knee OA. Our data were obtained from the large publicly available Osteoarthritis Initiative database and we used well established and validated measurements of HRQoL, ie, the SF-12 and the KOOS-QoL subscale. Examining the effects of falls on HRQoL outcomes is unique and contributes to a broader understanding of falls prevention in older adults. ${ }^{27}$ The limitations of this study include its crosssectional design, which prevents comparison of data over time. Further, the self-reported nature of the key variables, ie, selfreported falling and doctor-diagnosed knee $\mathrm{OA}$, and fall data being limited to a 12-month period limits the generalizability of the current findings. Self-reported doctor-diagnosed knee OA was not verified clinically or radiologically, except for cases where the doctor had confirmed the diagnosis, which introduces a degree of bias and makes it impossible to draw a reasonable conclusion. Even with adjusting for confounding between groups, there are still likely to be many unmeasured confounders in this type of analysis.

A better understanding of the relationship between falls, knee OA, and HRQoL is necessary to develop effective prevention and treatment programs..$^{32}$ For example, if future longitudinal research confirms that persons with falls and knee OA have worse HRQoL compared with persons who neither had experienced fall nor knee OA and either had experienced fall or knee OA, attention can be devoted to the types of educational and training materials that could assist them in reducing their risk of falling and knee OA. This particularly important for persons who had both a history of falling and knee OA, some of whom will required information in a bilingual format. ${ }^{33,34}$

\section{Conclusion}

We found that persons who had experienced falls and had knee OA experienced poorer HRQoL than those had no history of falling or knee OA and either a history of falling or knee OA. Falls and knee OA were significantly associated with both a lower KOOS-QoL subscale score and a lower PCS score on the SF-12, even after adjusting for sociodemographic, lifestyle, and clinical factors. Future populationbased longitudinal research is necessary in order to examine how HRQoL changes over time. This research is particularly important in underserved groups, such as those who are at high risk of falling and have knee OA.

\section{Acknowledgment}

The authors are grateful to the Research Centre, College of Applied Medical Sciences, and the Deanship of
Scientific Research at King Saud University for funding this research.

\section{Disclosure}

The authors report no conflicts of interest in this work.

\section{References}

1. Centers for Disease Control and Prevention. Falls among older adults: an overview. Atlanta, GA, USA: Centers for Disease Control and Prevention; 2013. Available from: http:/www.cdc.gov/homeandrecreationalsafety/Falls/adultfalls.html. Accessed April 4, 2014.

2. Bongue B, Dupre C, Beauchet O, Rossat A, Fantino B, Colvez A. A screening tool with five risk factors was developed for fall-risk prediction in community-dwelling elderly. J Clin Epidemiol. 2011; 64(10):1152-1160.

3. Thaler-Kall K, Döring A, Peters A, et al. Association between anemia and falls in community-dwelling older people: cross-sectional results from the KORA-Age study. BMC Geriatr. 2014;14(1):29.

4. Tromp AM, Pluijm SM, Smit JH, Deeg DJ, Bouter LM, Lips P. Fall-risk screening test: a prospective study on predictors for falls in communitydwelling elderly. J Clin Epidemiol. 2001;54(8):837-844.

5. Stevens JA, Ballesteros MF, Mack KA, Rudd RA, DeCaro E, Adler G. Gender differences in seeking care for falls in the aged Medicare population. Am J Prev Med. 2012;43(1):59-62.

6. Scott D, Blizzard L, Fell J, Jones G. Prospective study of self-reported pain, radiographic osteoarthritis, sarcopenia progression, and falls risk in community-dwelling older adults. Arthritis Care Res (Hoboken). 2012;64(1):30-37.

7. Prieto-Alhambra D, Nogues X, Javaid MK, et al. An increased rate of falling leads to a rise in fracture risk in postmenopausal women with self-reported osteoarthritis: a prospective multinational cohort study (GLOW). Ann Rheum Dis. 2013;72(6):911-917.

8. Arnold CM, Gyurcsik NC. Risk factors for falls in older adults with lower extremity arthritis: a conceptual framework of current knowledge and future directions. Physiother Can. 2012;64(3):302-314.

9. Centers for Disease Control and Prevention. QuickStats: Rate of nonfatal, medically consulted fall injury episodes by age group. Atlanta, GA, USA: Centers for Disease Control and Prevention; 2012. Available from: http://www.cdc.gov/mmwr/preview/mmwrhtml/mm6104a8.htm. Accessed April 4, 2014

10. Centers for Disease Control and Prevention. Arthritis policy: strategic directions. Atlanta, GA, USA: Centers for Disease Control and Prevention; 2011. Available from: http://www.cdc.gov/arthritis/resources/ policy.htm. Accessed April 4, 2014.

11. Hill CL, Parsons J, Taylor A, Leach G. Health related quality of life in a population sample with arthritis. J Rheumatol. 1999;26(9): 2029-2035.

12. Hickey A, Barker M, McGee H, O’Boyle C. Measuring healthrelated quality of life in older patient populations: a review of current approaches. Pharmacoeconomics. 2005;23(10):971-993.

13. Briem K. [Reliability, validity and responsiveness of the Icelandic version of the knee injury and osteoarthritis outcome score (KOOS)]. Laeknabladid. 2012;98(7-8):403-407. Icelandic.

14. Osteoarthritis Initiative. San Francisco, CA, USA: University of California, San Francisco; 2013. Available from: https:/oai.epi-ucsf. org/datarelease/. Accessed April 6, 2014.

15. OsteoArthritis Initiative. A knee health study. San Francisco, CA, USA: University of California, San Francisco; 2013 Available from: https://oai.epi-ucsf.org/datarelease/About.asp. Accessed March 4, 2014.

16. Lamb SE, Jorstad-Stein EC, Hauer K, Becker C. Development of a common outcome data set for fall injury prevention trials: the Prevention of Falls Network Europe consensus. J Am Geriatr Soc. 2005;53(9):1618-1622.

17. Fontaine KR, Haaz S, Heo M. Projected prevalence of US adults with self-reported doctor-diagnosed arthritis, 2005 to 2050. Clin Rheumatol. 2007;26(5):772-774. 
18. Andresen EM, Meyers AR. Health-related quality of life outcomes measures. Arch Phys Med Rehabil. 2000;81(12 Suppl 2):S30-S45.

19. Charlson ME, Pompei P, Ales KL, MacKenzie CR. A new method of classifying prognostic comorbidity in longitudinal studies: development and validation. J Chronic Dis. 1987;40(5):373-383.

20. Roos EM, Lohmander LS. The Knee Injury and Osteoarthritis Outcome Score (KOOS): from joint injury to osteoarthritis. Health Qual Life Outcomes. 2003;1:64.

21. Ware J Jr, Kosinski M, Keller SD. A 12-Item Short-Form Health Survey: construction of scales and preliminary tests of reliability and validity. Med Care. 1996;34(3):220-233.

22. Barlow JH, Wright CC. Dimensions of the Center of Epidemiological Studies-Depression Scale for people with arthritis from the UK. Psychol Rep. 1998;83(3 Pt 1):915-919.

23. Der-Martirosian C, Kritz-Silverstein D, Barrett-Connor E. Five-year stability in associations of health-related quality of life measures in community-dwelling older adults: the Rancho Bernardo Study. Qual Life Res. 2010;19(9):1333-1341.

24. Wesseling J, Welsing PM, Bierma-Zeinstra SM, et al. Impact of selfreported comorbidity on physical and mental health status in early symptomatic osteoarthritis: the CHECK (Cohort Hip and Cohort Knee) study. Rheumatology (Oxford). 2013;52(1):180-188.

25. Chen Y, Mo F, Yi Q, Morrison H, Mao Y. Association between mental health and fall injury in Canadian immigrants and non-immigrants. Accid Anal Prev. 2013;59:221-226.

26. Nicklett EJ. Sex, health behaviors and social support: functional decline among older diabetics. Am Med J. 2012;3(2).

27. Gerberding JL, Falk H, Arias I, Ballesteros M. Preventing falls: how to develop community-based fall prevention programs for older adults. Atlanta, GA, USA: Centers for Disease Control and Prevention; 2008. Available from: http://www.cdc.gov/HomeandRecreationalSafety/ images/CDC_Guide-a.pdf. Accessed April 5, 2014.
28. Mili F, Helmick CG, Moriarty DG. Health related quality of life among adults reporting arthritis: analysis of data from the Behavioral Risk Factor Surveillance System, US, 1996-1999. J Rheumatol. 2003;30(1):160-166.

29. Leveille SG, Bean J, Bandeen-Roche K, Jones R, Hochberg M, Guralnik JM. Musculoskeletal pain and risk for falls in older disabled women living in the community. J Am Geriatr Soc. 2002;50(4): 671-678.

30. [No authors listed]. Guideline for the Prevention of Falls in Older Persons. American Geriatrics Society, British Geriatrics Society, and American Academy of Orthopaedic Surgeons Panel on Falls Prevention. J Am Geriatr Soc. 2001;49(5):664-672.

31. Sturnieks DL, Tiedemann A, Chapman K, Munro B, Murray SM, Lord SR. Physiological risk factors for falls in older people with lower limb arthritis. J Rheumatol. 2004;31(11):2272-2279.

32. Muraki S. [Fall risk and fracture. The association of physical performance with falls in the elderly]. Clin Calcium. 2013;23(5):713-718. Japanese.

33. Koh HK. A 2020 vision for healthy people. $N$ Engl J Med. 2010; 362(18):1653-1656.

34. HealthyPeople.Gov. Health-related quality of life and well-being. Washington, DC, USA: US Department of Health and Human Services; 2010 Available from: http://healthypeople.gov/2020/about/ QoLWBabout.aspx. Accessed March 17, 2014.
Clinical Interventions in Aging

\section{Publish your work in this journal}

Clinical Interventions in Aging is an international, peer-reviewed journal focusing on evidence-based reports on the value or lack thereof of treatments intended to prevent or delay the onset of maladaptive correlates of aging in human beings. This journal is indexed on PubMed Central, MedLine,

\section{Dovepress}

CAS, Scopus and the Elsevier Bibliographic databases. The manuscript management system is completely online and includes a very quick and fair peer-review system, which is all easy to use. Visit http://www.dovepress. com/testimonials.php to read real quotes from published authors. 